\title{
Insights into public preferences for pharmaceutical funding
}

Jennifer A Whitty ${ }^{1}$, Sharyn R Rundle-Thiele ${ }^{2}$, Paul A Scuffham ${ }^{1}$

1. School of Medicine, Griffith University, Logan Campus L03 2.14, University

Drive, Meadowbrook 4131, Queensland, Australia. Ph: +61 (0)7 33821486 Fax: +61 (0)733821338

2. Faculty of Business, University of Southern Queensland, Springfield Campus, PO Box 4196, Springfield 4300, Queensland, Australia. Ph: +61 (0)7 34704539. Fax: $+61(0) 734704500$.

\section{Jennifer A. Whitty (corresponding author)}

Jennifer Whitty is a pharmacist who has specialised in the field of pharmacoeconomics. She is currently a lecturer in Health Economics at Griffith University. Email: j.whitty@griffith.edu.au

\section{Associate Professor Sharyn R. Rundle-Thiele}

Sharyn Rundle-Thiele is an Associate Professor of Marketing at the University of Southern Queensland. Her expertise is in 1) customer loyalty and retention strategies and 2) decision making and 3) corporate social responsibility. She has published more than 70 articles in these areas and she has undertaken numerous market research and strategy consultancies in a wide range of industries. Email: rundle@usq.edu.au

\section{Professor Paul A. Scuffham}

Paul Scuffham is the Professor of Health Economics at Griffith University. His expertise is in health technology assessment and the economics of healthcare delivery. He has published more than 60 articles in academic journals and undertaken numerous consultancies for pharmaceutical companies and government agencies. Email: p.scuffham@griffith.edu.au 


\section{Acknowledgements:}

The authors would like to thank those who participated in this study. Jennifer Whitty gratefully acknowledges the support of Griffith University Postgraduate and School of Medicine PhD scholarships to undertake this study as a part of her doctoral research. The thoughtful comments from the reviewers of this manuscript played a pivotal role in the final shaping of this article. Thankyou for your assistance. 


\title{
Insights into public preferences for pharmaceutical funding
}

\author{
Abstract \\ Purpose \\ Taxes are used to subsidise the public use of pharmaceuticals in some \\ countries. This study sought to quantify criteria considered important by the \\ Australian public for allocating resources for pharmaceuticals.
}

\section{Methodology}

A Discrete Choice Experiment (DCE) was administered to two samples of adults in Australia. A forced choice design was used in a pilot study, but an opt-out option was included in the main study to avoid forcing choice. Data were analysed using Multinomial Logit.

\section{Findings}

For the levels and units presented in the DCE, quality of life (QoL) after treatment was the most important attribute in both the pilot and main studies, followed by survival after treatment and the chance of success for a given pharmaceutical. Cost to the government was of little importance in the pilot study, but was of importance in the main study.

\section{Implications}

By understanding public preferences, marketers can tailor pharmaceutical offerings that appeal to the public and to relevant pharmaceutical funding bodies when making submissions, thus increasing the likelihood of receiving public funding support. Understanding public preferences allows public policy-makers to direct resources towards those medical technologies which are likely to give the greatest overall societal benefit.

\section{Originality / value of paper}

This study shows the simultaneous importance of survival, QoL, chance of success, and cost to public preferences for pharmaceutical funding. Cost (tax) signals suggest the public are willing to limit the amount they expect the government to pay for effective pharmaceuticals. 


\section{Keywords:}

Preferences, Pharmaceuticals, Priority setting, Decision-making, Discrete Choice Experiment, Multinomial Logit Model

Paper classification: Research paper

Words in text: 4,579 (excludes abstract, references and tables/figures)

Date: Final revision $30^{\text {th }}$ June 2008 


\section{Background}

Some developed countries have turned to health technology assessment (HTA) in an attempt to limit ever increasing public expenditure (WHO, 2006) and to improve the efficiency and equity of access to the health care system. Australia has been a leader in this HTA field. The Pharmaceutical Benefits Advisory Committee (PBAC) has required an assessment of the cost-effectiveness of each pharmaceutical seeking government funding support for more than fifteen years (Mitchell, 2002). Such decisions require criteria to compare proposals for various pharmaceuticals seeking funding. Given the PBAC is responsible for determining how best to allocate tax payers resources, there is a need to consider the preferences of the public contributing these funds. Economic theory suggests that societal welfare is maximised when resources are allocated according to consumer preferences (Garber et al., 1996). There is a general consensus that preferences for resource allocation decisions across competing programs should be taken from a representative sample of the entire population who pay for and are eligible to benefit from the resource(s) (Gold et al., 1996; National Institute for Health and Clinical Excellence, 2004; Pharmaceutical Benefits Advisory Committee, 2007; Robinson and Parkin, 2002; Ryan et al., 2001). Further, judgements regarding funding recommendations for pharmaceuticals are social as well as scientific in nature (National Institute for Health and Clinical Excellence, 2005; Rawlins, 2005), and public consultation is consistent with the principles of procedural justice (Daniels and Sabin, 2002; Rawlins, 2005). Studies seeking public opinion provide some indication that the public want their preferences to be considered for "non-technical" aspects of priority-setting (Ryan et al., 2001; Wiseman et al., 2003).

There is a growing realisation that the public do not want decisions to be based on cost-effectiveness alone, if at all. This realisation stems from the Oregon experience in 1990, where a draft "league table" for health care services, based on cost-effectiveness alone, produced counter-intuitive priorities (Hadorn, 1991). More recently, there has been a proliferation of studies supporting the importance, to the public, of other criteria (Dolan et al., 2005; Dolan and Tsuchiya, 2006; Schwappach, 2002). In particular, it appears the public are concerned with criteria related to equity 
and fairness. For example, there is a preference to prioritise younger patients (Dolan et al., 2005; Johri et al., 2005; Nord et al., 1996; Rodriguez and Pinto, 2000; Schwappach, 2002, , 2003; Tsuchiya, 1999), those with severe illness (Gyrd-Hansen, 2004; Johri et al., 2005; Nord, 1993; Ubel et al., 1996), and the public are not indifferent to how the gain is distributed, preferring a reduction of inequality and wide dispersion of resources (Bleichrodt et al., 2005; Dolan et al., 2005; Rodriguez-Miguez and Pinto-Prades, 2002; Schwappach, 2002; Ubel et al., 2000). However, less is known regarding public preferences for more technical criteria, such as those relating to the effectiveness and cost of a pharmaceutical. The research presented in this paper sought to quantify technical criteria considered by the Australian public for allocating resources for pharmaceuticals.

\section{An overview of the literature on public preferences for pharmaceutical effectiveness and cost}

Studies have been undertaken in Australia in both generic contexts of resource allocation or priority setting between competing healthcare programs (Mooney and Blackwell, 2004; Mortimer and Segal, 2008; Nord et al., 1995; 1996; Wiseman, 2004), and specific resource allocation contexts (Alexander and Hicks, 1998; Browning and Thomas, 2001). To date, only one study (see Gallego et al., 2007) has been undertaken in Australia in a pharmaceutical context (prioritising access to high cost medications). A total of twelve criteria were identified with empirical support for their importance for resource allocation decisions. Criteria of importance are the intervention type, effectiveness, cost-effectiveness, evidence base and novelty; the recipient's severity of illness, age, socio-economic status, whether they were responsible for their own illness and whether they have dependents; and the reduction of inequality and wide distribution of a fixed gain within society.

Although it is clear that the public (in Australia and elsewhere) place some importance on the effectiveness of a healthcare intervention (Alexander and Hicks, 1998; Browning and Thomas, 2001; Bryan et al., 2002; Gallego et al., 2007; GyrdHansen, 2004; Mortimer and Segal, 2008; Nord, 1993; Nord et al., 1995; 1996; Schwappach, 2003), few studies have quantified the public's willingness to trade 
between the individual components of effectiveness (that is, survival, quality of life, and chance of success) for the treatment of others (Bryan et al., 2002; Schwappach, 2003). Further, although findings from a deliberative study incorporating a prioritysetting exercise and from a stated preference study undertaken in a generic context suggest the public are willing to consider cost-effectiveness as a priority-setting criterion in some situations (Gold et al., 2007; Mortimer and Segal, 2008), this is to some extent inconsistent with an opinion-based study of Australian preferences, which concluded that costs should not be a major factor in prioritising healthcare (Nord et al., 1995). To our knowledge, no stated preference study has attempted to quantify the willingness of the public to use cost or cost-effectiveness as a decisionmaking criterion for pharmaceutical funding. This is despite the apparent importance of these criteria to the public decision-making process.

The aim of this study was to consider the importance to the public of criteria for resource allocation for pharmaceuticals. In particular, the study aimed to quantify the importance of survival, quality of life (QoL), chance of success, and government costs, in the context of social decision-making for pharmaceutical funding. We present the findings of a discrete choice experiment (DCE) that was piloted using a convenience sample, amended to include an opt-out option, and administered using a quasi-random population sample in Australia.

\section{Method}

The DCE is a stated preference technique which has been used for many years in marketing research and transport economics (Kjaer, 2005). The DCE was chosen as the most suitable technique for this study for a number of reasons. In particular, as a choice-based technique it presents a familiar task to respondents and incorporates opportunity cost; and further, it allows exploration of the relative contribution of multiple attributes to overall preferences (Farrar et al., 2000; Hanley et al., 2001; Ryan, Gerard et al., 2006). Over the last decade, the DCE has become established as a technique to analyse preferences in healthcare (see for example Ryan and Gerard, 2003 for a review of the use of the DCE in healthcare and more recently Brau and Bruni, 2008; Haas, 2005; Hall et al., 2006; Johnson and Backhouse, 2006; King et al., 
2007; Lancsar et al., 2007; Mantovani et al., 2005; Ryan Netten et al., 2006; Ryan and Skatun, 2004; Tappenden et al., 2007). However, to our knowledge this is the first use of a DCE to explore public preferences for pharmaceutical funding.

\section{Survey design}

A DCE was developed for a current practice scenario where an individual could be considered to have severe illness, as described by an expected survival of 3 months in extreme pain/discomfort with current treatment. In an initial pilot study, respondents were asked which of two medications (A or B) they would prefer the government to fund from money raised via public taxes. However, following feedback from the pilot study, respondents in a quasi-random population sample were given a third opt-out option of "neither" to better reflect current practice. Thus, should respondents view the described pharmaceuticals as unworthy of funding, they were not forced to make a choice. Therefore, the resulting model represents unconditional demand for a new pharmaceutical (Hensher et al., 2005).

Each pharmaceutical was described using four different attributes: chance of success (SUCCESS), survival if successful (SURVIVAL), quality of life if successful (QoL) and cost per person treated (COST). The chosen attributes represented criteria that were identified from a review of the literature (Bryan et al., 2002; Dolan et al., 2005; Gold et al., 2007; Gyrd-Hansen, 2004; Nord et al., 1995; Nord et al., 1996; Schwappach, 2002, 2003) as likely to be important to the public for funding decisions, and which addressed the study purpose. Other criteria considered likely to be important to the decision (recipient age, number treated) were held constant (at 50 years, 5,000 respectively) in the introductory text describing the scenario for the DCE. This minimised the cognitive demand placed on respondents (by minimising the number of attributes varying between alternatives), whilst avoiding the introduction of missing attribute bias (Kjaer, 2005). Each attribute was described by a number of different levels which varied between alternative pharmaceuticals. Levels for each attribute were identified through the literature (Bryan et al., 2002; Nord et al., 1996; Schwappach, 2003; Williams, 1995) and expert opinion. A summary of the attributes and levels used in the pilot and main DCE are provided in Table 1. 


\section{Take in Table 1 about here}

Introductory text was presented at the start of the DCE, to inform respondents of the decision context (see Figure 1). A fractional factorial additive main effects design was used (Hensher et al., 2005). The first alternative in each choice set was obtained from an orthogonal array, developed using Orthoplan ${ }^{\mathrm{TM}}$ in SPSS (SPSS, 2005). The second alternative in each set was developed manually from the orthogonal array using the Shifted Design technique, which has been shown to produce efficient designs for generic forced choice DCEs (Bunch et al., 1996). This resulted in 9 choice sets which were presented to each respondent. An example choice question is given in Figure 2. In addition to the choice experiment, respondents were asked some questions to indicate their socio-demographic status. This was to enable a comparison of the sample characteristics with those of the general Australian population.

\section{Take in Figure 1 and Figure 2 about here}

\section{Data collection}

1. Pilot study

Ethics approval was obtained for the study. The forced choice DCE instrument was administered in person ${ }^{[1]}$ to an adult convenience sample $(n=19)$ in Australia in 2006. The number of observations available for analysis (171) was judged to be sufficient as this study was exploratory in nature. A \$10 gift was offered to thank respondents for their participation.

\section{Main study}

The DCE instrument including a third "neither" option was self-administered as a postal survey. An independent marketing company mailed the questionnaire to "the resident" at a quasi-random sample of 1,000 Australian households in March 2007. The addresses were identified from an electronic copy of the Australian white 
pages telephone directory. Entry into a prize draw for a one in fifty chance of winning a $\$ 100$ gift voucher was offered as an incentive to respondents for participation.

\section{Data analysis}

Data analysis was undertaken using SPSS version 14 (SPSS, 2005) and NLOGIT version 4.0 (Greene, 2007). The parameters indicating attribute importance were estimated using a Multinomial Logit (MNL) model (Hensher et al., 2005). All attributes except QoL were coded as continuous variables (Table 1), and the models assumed linear main effects for each of these attributes (Hensher et al., 2005). The QoL attribute was effects coded with the worst level (extreme pain/discomfort) coded as the omitted level (Hensher et al., 2005). The variable QoLE1 was associated with the best level for QoL (no pain/discomfort), and QoLE2 was associated with the middle level of QoL (moderate pain/discomfort). Effects coding was used since it permits computation of effect size for each attribute level including the omitted level (Hensher et al., 2005; Phillips et al., 2002). It was expected, a priori, that the estimated coefficients for SUCCESS, SURVIVAL, and QoLE1 ${ }^{[2]}$ would be positive, whilst the coefficient for COST would be negative. For the main study, an alternative specific constant was assigned to the "neither" alternative (Hensher et al., 2005).

Model fit was assessed using the pseudo $\mathrm{R}^{2}$ and Log-likelihood (LL) ratio tests; statistical significance of each attribute was assessed using a Wald test (Hensher et al., 2005).

\section{Findings}

For the main study, 15 surveys were returned undelivered. Of the remaining 985 surveys, 163 were returned of which 2 were not usable. Thus, the useable response rate was $16.3 \%$ (161 out of 985). The sample size is comparable with other marketing or health care discrete choice experiments (see Arora, 2006; Mantovani et al., 2005; Ryan and Farrar, 2000) and exceeds other discrete choice or conjoint-based 
experiments (see Dean, 2004; Haas, 2005; Johnson and Backhouse, 2006; King et al., 2007; Koo et al., 1999; Lancsar et al., 2007; Tappenden et al., 2007).

\section{Respondent characteristics}

A summary of the respondent characteristics for both the pilot and main studies is given in Table 2 .

\section{Take in Table 2 about here}

The pilot sample was not intended to be representative of the Australian population. When compared to the Australian population people sampled were more likely to be female, younger, not health insured, with lower household income than the average Australian (Australian Bureau of Statistics, 2003-04, 2004-05, 2006b). Furthermore, those with a degree or professional qualification were over-represented in this convenience sample when compared to Australian population data (Australian Bureau of Statistics, 2006a).

The main study respondent sample $(n=161)$ had a mean age of 53.6 years and contained slightly more females $(58.5 \%)$ than males $(41.5 \%)$. All household income categories were represented. Postcodes provided by the respondents suggested that all Australian states were represented. The majority of respondents lived in highly accessible $(83.5 \%)$ or accessible $(12.7 \%)$ areas as categorised by the Accessibility/Remoteness Index of Australia (ARIA) (Department of Health and Aged Care, 2001). Despite the quasi-random recruitment approach, the sample can not be considered to represent the Australian population. In particular, the main study sample was on average older, more likely to be female, have a degree or professional qualification, have a higher household income, and have private health insurance, when compared to Australian population data (Australian Bureau of Statistics, 200304, 2004-05, 2006a, 2006b). It is also likely to under-represent indigenous Australians and those living in remote areas.

There were some apparent differences in the characteristics of the pilot and main study sample. In particular, the main study sample was on average older and 
more likely to have a higher household income and private health insurance than the pilot study sample.

\section{Choice observations}

In the pilot study, 166 choice observations were available from a total of 171 choice sets. Two respondents did not respond to a total of 5 choice sets, stating they would prefer to choose "neither"[3]. For this reason a neither option was included in the main choice study. For the main study, a total of 1440 valid choice observations were obtained from a possible 1449 choice sets. The other 9 choice sets appeared to have been missed in error, where respondents had not indicated any choice on a page. The majority of respondents $(86,53.4 \%)$ always chose a new pharmaceutical (A or B). The remaining 75 respondents chose "neither" on a total of 239 occasions. The overall mean was 1.48 "neither" responses per respondent; however, the data were right skewed with $22(13.7 \%)$ choosing "neither" once and only 1 respondent $(<0.1 \%)$ choosing neither on all nine occasions.

\section{Model fit}

The results of the MNL models for both the pilot and main studies are shown in Table 3 . The LL ratio tests for both the pilot and main study models indicated that the estimated models explained a larger proportion of the variance of the choice decision than did the base (constants only) model. The pseudo $\mathrm{R}^{2}$, after adjustment for the degrees of freedom, was $40 \%$ in the pilot study and $28 \%$ in the main study, indicating an acceptable fit for both models (Hensher et al., 2005).

\section{Take in Table 3 about here}

\section{Model coefficients}

With the exception of COST in the pilot study model, all regression coefficients had the expected sign, and were statistically significant $(\mathrm{p}<0.05$; Table 3$)$. In the pilot study model, COST had a positive sign but was not statistically 
significant. Consistent with expectations, the regression coefficient for QoLE1 was greater than for QoLE2 for both models. For the main study, the coefficient for the constant associated with the "neither" alternative was positive and significant, indicating a propensity to choose "neither" over a new pharmaceutical (A or B), all else equal.

The regression coefficients indicated that QoL had the strongest influence on respondent's choice behaviour, followed by survival, chance of success, and cost. This was the case for both the pilot and main study models. Cost to the government was not significant in the pilot study, but was significant in the main study.

\section{Interpreting the choice probability}

Since QoL had the strongest influence on respondents' choice behaviour, it was varied for both the pilot and main study models to provide an example of how the models can be used to estimate the probability of a respondents' choice to fund a hypothetical pharmaceutical, and to compare that probability across samples. In the first hypothetical choice set, holding all attributes except QoL at their worst level, the probability the public would want a pharmaceutical that improves QoL to its best level was $93 \%$ for the pilot study model and $63 \%$ for the main study model, when compared to a pharmaceutical which leaves recipients at the worst described level of QoL (for which the funding probabilities are 7\% and 3\% respectively) (Table 4). In the second hypothetical choice set, we find that setting all other attributes to their best level compensates somewhat for a poor QoL in both models, taking the funding probability for a pharmaceutical that leaves recipients in the worst state of QoL to $25 \%$ in the pilot study model (from $7 \%$ ) and to $28 \%$ in the main study model (from $3 \%$ ) (Table 4).

Take in Table 4 about here 


\section{Discussion}

According to this research the Australian public view the quality of life after treatment, survival after treatment, and chance of success associated with a new pharmaceutical to be important considerations when funding pharmaceuticals for the treatment of others suffering a severe illness. This was the case for both a small convenience sample and a larger population sample whose characteristics were quite different in terms of their socio-demographic profile. Further, the order of importance of these three attributes (as defined by the size of their coefficients in the model) was consistent between the two (pilot and main study) models suggesting the findings can be considered to be robust. The importance of quality of life, survival and chance of success to decisions regarding the treatment of others is consistent with the findings of others exploring British and German preferences (Bryan et al., 2002; Schwappach, 2003).

A novel finding of this study is that when framed in terms of a government tax fund payment vehicle, the cost of the pharmaceutical is important to the respondents. To our knowledge, this is the first stated preference study that has explored the impact of cost on public preferences for pharmaceutical funding decisions. It might be hypothesised that cost, when framed in this way (i.e. where the payer is a public source, not the respondent themselves), might be unimportant to preferences. However, for the main study, the cost attribute did contribute significantly to the model. This indicates the public are in fact able to consider public funds as a payment vehicle. The public's willingness to use cost as a decision-making criterion is consistent with the findings of an American deliberative study (Gold et al., 2007), but is to some extent inconsistent with previous opinion-based research in Australia (Nord et al., 1995). The cost to the government did not contribute significantly to the decision in the pilot study. There are three possible explanations for this. Firstly, the pilot study respondents represented a subgroup of the population who were quite different in characteristic from the main study respondents; it may be that the importance of cost varies between population subgroups. Secondly, the small number of observations from the pilot sample may not have been sufficient to show a statistical result for the COST coefficient, particularly given the likely small effect size (as evidenced in the main study). Thirdly, the pilot study utilised a forced choice 
design; this may have resulted in a choice to fund a new pharmaceutical which in reality the respondent did not value. As a consequence, the COST attribute may have (inappropriately) appeared insignificant. Further confirmation of the importance of government costs to the public should be sought; however, this study is indicative that the public are willing to place a limit on the amount they consider the government should pay for a health gain.

The findings of this study highlight the importance of considering the inclusion of an opt-out option in DCEs related to priority-setting generally and pharmaceutical funding specifically. Qualitative comments from the pilot study indicated some respondents wished to be able to choose "neither". Therefore, the DCE design for the main public study included an option to fund "neither" new pharmaceutical. Thus, should respondents view the described pharmaceuticals as unworthy of funding, they were not forced to make a choice. When presented with a "neither" option, respondents in the main study utilised that choice an average of 1.48 times (from 9 choice sets). Thus, "neither" was selected sufficiently often to be a valued option, yet use of the option was not excessive. One of the concerns associated with the inclusion of an opt-out option is that it might be utilised as a mechanism for decision avoidance (Anderson, 2003; Redelmeier and Shafir, 1995); there was no evidence to suggest this occurred in the current study.

Conditional demand models (i.e. those that force a choice) can overestimate the uptake of new goods and services in the market place (Ryan and Skatun, 2004). In the current DCE, this suspicion is confirmed by examining the consequence of the inclusion of the "neither" alternative on the choice probabilities from the two (i.e. pilot study and main study) models. We have presented an example indicating the probability of funding hypothetical pharmaceuticals, which assigned a considerable probability of choosing "neither" pharmaceutical (with consequence for the uptake of the hypothetical pharmaceutical) in two alternative choice sets. Previous conjointbased studies exploring public preferences for health gain have not allowed an option to fund neither (Bryan et al., 2002; Mortimer and Segal, 2008; Schwappach, 2003); this may have biased the importance of their attributes. 


\section{Limitations and future research implications}

The main limitation of this study relates to generalizability. The findings of the main study may be limited by the response rate (16.3\%), which is slightly lower than other studies involving self-administered surveys (Bennett and Rundle-Thiele, 2004; Rundle-Thiele, 2005). Further, the results may be biased by a sample who show an above average interest in the funding of pharmaceuticals (Dillman, 2000). For example, individuals using prescription medicines, or experiencing some degree of pain/discomfort, may have been more likely to respond. Future research could consider face to face administration to increase response rate and test for nonresponse error. Further, despite the quasi-random recruitment method for the main study, respondents do not appear to be strictly representative of the Australian adult population. Of particular note, respondents were more likely to have private health insurance (72.3\% hospital cover, $66.0 \%$ ancillary cover) than the average Australian (46.6\% hospital cover, $41.4 \%$ ancillary cover) (Australian Bureau of Statistics, 200405). Despite these possible limitations, the considerable similarities (in terms of coefficient significance, size and order of attribute importance) between the models for the pilot study and the main public study, despite the differences in sample characteristics (especially with respect to the age, income and health insurance profiles) suggest that the findings are robust for the sampled populations.

It is possible that respondents may have implicitly discounted survival benefits. Therefore, the findings of the model may be confounded by the respondents' time preference. However, the survival durations used in the DCE were 3 months, 1 year and 10 years (the largest duration), with all survival gains commencing after 3 months (which was the average time individuals were expected to survive with current treatment). Quality of life gains also commenced in 3 months and lasted for the duration of survival. Therefore, it seems unlikely that any implicit discounting of survival would have a large impact on the findings of this study. Nevertheless, identifying any implicit discounting or designing scenarios with explicitly discounted outcomes is an area for future research. 


\section{Practical implications}

Implications are evident for both pharmaceutical marketers and public policy makers. Firstly, by understanding public preferences pharmaceutical marketers can tailor pharmaceutical offerings that appeal to the public. Using this scenario as an illustrative example, pharmaceutical marketers would seek to emphasise quality of life after treatment in funding submissions. These preferences can be communicated to relevant pharmaceutical funding bodies when making initial funding submissions, thus increasing the likelihood of receiving public funding support. Secondly, an understanding of public preferences allows public policy-makers to direct resources towards those medical technologies which are likely to give the greatest overall societal benefit. Preference elicitation provides one of a number of complimentary mechanisms for public consultation in policy-making.

The results of this study suggest that when considering resource allocation for the treatment of others with pharmaceuticals, the public value quality of life after treatment, survival after treatment and chance of success, and people may be prepared to trade survival to gain quality of life (and vice versa) when illness is severe (i.e. described as a short survival in extreme pain/discomfort). This is to some extent consistent with the use of the Quality-Adjusted Life Year (QALY), which trades survival for quality of life, as an outcome measure in economic evaluation ${ }^{[4]}$ (Scuffham et al., 2008). Finally, the findings suggest that cost is of relatively little importance when compared to other factors (e.g. quality of life and survival) to the public when "rescuing" persons from a short expected survival in a poor initial health state. However, it is not unimportant, and it appears that the public are willing to trade between cost and effectiveness, even when the payment vehicle is not out of their own pocket. Broadly, this supports the use of cost-effectiveness as one decisionmaking criterion in the public funding process for pharmaceuticals.

This study was undertaken in an Australian context. There is some consistency between the findings in this study and those of studies undertaken in the United Kingdom, Germany or United States in terms of the publics' willingness to trade between survival, quality of life and chance of success (Bryan et al., 2002; Schwappach, 2003) or in terms of the relevance of cost (Gold et al., 2007). 
Nevertheless, further research is needed to confirm the findings of this study in other preference populations. The research reported in this paper used criteria related to effectiveness and cost. A review of the literature suggests there are other criteria of importance. Future research is required to explore other criteria of importance. Further, this study used a severe illness scenario. Future research is required in other health scenarios. Examples may include chronic illness or prevention. Taken together, these research endeavours would enable a more comprehensive picture of public preferences for pharmaceutical funding to emerge.

\section{Conclusion}

The public are willing and able to provide preferences to inform policy for pharmaceutical decision-making. The results of this study suggest the Australian public value the expected quality of life, expected survival and chance of success associated with a pharmaceutical used to treat others in severe illness. They do not expect the government to purchase health gain at any cost. The inclusion of an optout option should be considered in future discrete choice experiments in prioritysetting generally and related to pharmaceutical funding specifically. This study sets the foundations for further research into public preferences for pharmaceutical funding. 
Two new prescription medications have been developed. They are suitable for use in a group of 5,000 adults who all have the same medical condition. The average age of the adults is 50 years. With current treatment, which is effective in all adults, the adults will on average live for another 3 months with extreme pain/discomfort. The two new medications vary in terms of the chance that the treatment will be successful, and the average length of life and quality of life the adults will have after successful treatment. The average additional cost to the government per person treated also varies, and this cost applies regardless of whether or not treatment was successful.

The government has a limited budget and only one of the medications can be funded from money raised via public taxes. Each person will receive the chosen medication; that is, either medication A or medication B. If neither medication is funded, or if the new medication is unsuccessful, the adults will still be able to receive the current treatment, which you can assume to have no additional costs.

Figure 1: Introductory text from main study 


\begin{tabular}{|l|c|l|}
\hline Medication A & Medication B \\
\hline $90 \%$ & Chance of success & $60 \%$ \\
\hline 1 year & Survival & 10 years \\
\hline No pain/discomfort & Quality of life & Extreme pain/discomfort \\
\hline $\begin{array}{c}\text { \$100,000 } \\
\text { Please tick one box. I would prefer the government to fund: }\end{array}$ & Medication B \\
Medication A & Neither \\
\\
$\square$
\end{tabular}

Figure 2: Example choice question from main study 
Table 2: Respondent characteristics for the pilot study (n=19) and main study $(n=161)$

\begin{tabular}{|c|c|c|c|}
\hline \multirow[t]{2}{*}{ Characteristic } & \multirow[t]{2}{*}{ Category } & \multicolumn{2}{|c|}{ N (valid\%) or Mean (SD) } \\
\hline & & Pilot study & Main study \\
\hline Age (yrs) & & $\begin{array}{r}\text { Mean 36.84 } \\
\text { (SD 15.79) }\end{array}$ & $\begin{array}{r}\text { Mean 53.55 } \\
\text { (SD 14.47) }\end{array}$ \\
\hline Gender & Female & $11 \quad(57.9 \%)$ & $93 \quad(58.5 \%)$ \\
\hline \multirow[t]{3}{*}{ Education } & $\begin{array}{l}\text { Continued after minimum school } \\
\text { leaving age }\end{array}$ & $18 \quad(94.7 \%)$ & $(77.6 \%)$ \\
\hline & Degree/professional qualification & $9 \quad(47.4 \%)$ & $(52.5 \%)$ \\
\hline & Ever studied subject related to health & $\begin{array}{ll}5 & (26.3 \%) \\
\end{array}$ & $(26.7 \%)$ \\
\hline \multirow{6}{*}{$\begin{array}{l}\text { Employment } \\
\text { (main } \\
\text { activity) }\end{array}$} & Employed & $9 \quad(47.4 \%)$ & $(47.2 \%)$ \\
\hline & Retired & $3 \quad(15.8 \%)$ & $(29.8 \%)$ \\
\hline & Housework & $0 \quad(0 \%)$ & $(9.9 \%)$ \\
\hline & Student & $3 \quad(15.8 \%)$ & $(3.7 \%)$ \\
\hline & Seeking work & $0 \quad(0 \%)$ & $(1.9 \%)$ \\
\hline & Other* & $4 \quad(21.1 \%)$ & $(7.5 \%)$ \\
\hline \multirow{6}{*}{$\begin{array}{l}\text { Household } \\
\text { income (\$) }\end{array}$} & $\leq 25,000$ & $3 \quad(17.6 \%)$ & $(13.9 \%)$ \\
\hline & $25,001-50,000$ & $7 \quad(41.2 \%)$ & $(19.9 \%)$ \\
\hline & $50,001-75,000$ & $4 \quad(23.5 \%)$ & $(22.5 \%)$ \\
\hline & $75,001-100,000$ & $1 \quad(5.9 \%)$ & $(18.5 \%)$ \\
\hline & $100,001-125,000$ & $(5.9 \%)$ & $(15.2 \%)$ \\
\hline & $>125,000$ & $(5.9 \%)$ & $(9.9 \%)$ \\
\hline \multirow[t]{6}{*}{ State } & $\begin{array}{l}\text { New South Wales or Australian Capital } \\
\text { Territory }\end{array}$ & \multirow{6}{*}{$\begin{array}{l}\text { State was not } \\
\text { collected for the } \\
\text { pilot study }\end{array}$} & $(21.5 \%)$ \\
\hline & Victoria & & $(21.5 \%)$ \\
\hline & Queensland & & $(27.2 \%)$ \\
\hline & South Australia & & $(13.3 \%)$ \\
\hline & Western Australia & & $(14.6 \%)$ \\
\hline & Tasmania & & $(1.9 \%)$ \\
\hline \multirow{2}{*}{$\begin{array}{l}\text { Private health } \\
\text { insurance }\end{array}$} & Hospital cover & $6 \quad(31.6 \%)$ & $(72.3 \%)$ \\
\hline & Extras cover & $4(22.2 \%)$ & $(66.0 \%)$ \\
\hline
\end{tabular}

* Category 'other' includes those who indicated more than one of the above categories.

\# Total percentage exceeds $100 \%$ as categories within employment and insurance were not mutually exclusive. 
Table 3: Results for MNL model for pilot and main study with QoL effects coded, all other attributes coded as continuous variables

\begin{tabular}{|c|c|c|c|c|c|c|}
\hline \multirow[t]{2}{*}{ Variable } & \multicolumn{3}{|l|}{ Pilot study model } & \multicolumn{3}{|l|}{ Main study model } \\
\hline & $\beta$ & $\mathrm{SE}$ & $\mathrm{P}[1 \mathrm{Zl}>\mathrm{z}]$ & $\beta$ & $\mathrm{SE}$ & $\mathrm{P}[\mathrm{lZl}>\mathrm{z}]$ \\
\hline SUCCESS & 0.0216 & 0.0092 & $* 0.0188$ & 0.0109 & 0.0027 & $* * 0.0001$ \\
\hline SURVIVAL & 0.1289 & 0.0324 & $* * 0.0001$ & 0.1748 & 0.0123 & $* *<0.0001$ \\
\hline QoLE1 (no pain/discomfort) & 1.0024 & 0.1893 & $* *<0.0001$ & 1.1668 & 0.0746 & $* *<0.0001$ \\
\hline QoLE2 (moderate pain/discomfort) & 0.6173 & 0.1894 & $* * 0.0011$ & 0.6084 & 0.0624 & $* *<0.0001$ \\
\hline COST & 0.0038 & 0.0036 & 0.2830 & -0.0042 & 0.0011 & $* * 0.0002$ \\
\hline CONSTANT (“neither”) & & & & 1.4535 & 0.1686 & $* *<0.0001$ \\
\hline No. observations: & & & 166 & & & 1440 \\
\hline LL - estimated model & & & -65.35087 & & & -1051.712 \\
\hline LL - base model & & & -113.0179 & & & -1472.7246 \\
\hline No. parameters & & & 5 & & & 6 \\
\hline Pseudo- $\mathrm{R}^{2}$ & & & 0.42177 & & & 0.2859 \\
\hline Pseudo $\mathrm{R}^{2}$ adjusted & & & 0.40381 & & & 0.2844 \\
\hline $\begin{array}{l}\text { LL ratio test: } \\
\mathrm{H}_{0}: \beta_{1}=\beta_{2}=\beta_{3}=\beta_{4}=\beta_{5}=0 \\
\text { (a) }-2(\text { LLbase }- \text { LLestimated) } \ldots \ldots \ldots \\
\text { (b) Chi critical value................. } \\
\text { Outcome....................... }\end{array}$ & & & $\begin{array}{r}95.33 \\
9.49 \\
\text { (a) }>(\mathrm{b}), \text { reject } \mathrm{H}_{\mathrm{o}} \\
\end{array}$ & & & $\begin{array}{r}842.03 \\
11.07 \\
(\mathrm{a})>(\mathrm{b}), \text { reject } \mathrm{H}_{\mathrm{o}} \\
\end{array}$ \\
\hline
\end{tabular}

Table footnotes:

*significant at the $5 \%$ level (alpha 0.05 ). $\quad * *$ significant at the $1 \%$ level (alpha 0.01 ).
Abbreviations: $\beta$ is regression coefficient for the variable; SE is standard error for the coefficient; LL is Log Likelihood function; $\mathrm{H}_{0}$ is the null hypothesis being tested.

$\mathrm{P}[\mathrm{ZZl}>\mathrm{z}]$ represents the $\mathrm{p}$-value for the Wald test, the Wald test statistic is $\beta / \mathrm{SE}$ (Hensher et al., 2005).

Base model is constants only model.

Pseudo-R ${ }^{2}$ 1- [LL estimated model /LL base model] (Hensher et al., 2005).

Chi critical value refers to an alpha level of 0.05 , and a difference of 4 (pilot study) or 5 (main study) degrees of freedom between the estimated and base models. 
Table 4: Probability that a respondent in the pilot and main public samples would want a described hypothetical pharmaceutical funded

\begin{tabular}{|c|c|c|c|c|c|c|c|c|}
\hline \multirow[b]{2}{*}{ Alternative } & \multicolumn{4}{|c|}{ Pilot study sample } & \multicolumn{4}{|c|}{ Population sample } \\
\hline & QOL level & $\begin{array}{l}\begin{array}{l}\text { Other attribute } \\
\text { levels }\end{array} \\
\end{array}$ & $\begin{array}{l}\text { Systematic } \\
\text { utility (V) }\end{array}$ & $\begin{array}{l}\text { Probability of } \\
\text { funding (Pr) }\end{array}$ & QOL level & $\begin{array}{l}\text { Other attribute } \\
\text { levels }\end{array}$ & $\begin{array}{l}\text { Systematic } \\
\text { utility (V) }\end{array}$ & $\begin{array}{l}\text { Probability of } \\
\text { funding (Pr) }\end{array}$ \\
\hline \multicolumn{9}{|c|}{ Choice set one } \\
\hline 1 & $\begin{array}{l}\text { Best (no } \\
\text { pain/discomfort) }\end{array}$ & \multirow{2}{*}{$\begin{array}{l}\text { Worst } \\
\text { (SUCCESS } 60 \% \\
\text { SURVIVAL 3mth, } \\
\text { COST } \$ 100,000 \text { ) }\end{array}$} & 2.7106 & $93 \%$ & $\begin{array}{l}\text { Best (no } \\
\text { pain/discomfort) }\end{array}$ & \multirow{2}{*}{$\begin{array}{l}\text { Worst } \\
\text { (SUCCESS 60\%, } \\
\text { SURVIVAL 3mth, } \\
\text { COST } \$ 100,000 \text { ) }\end{array}$} & 1.4445 & $63 \%$ \\
\hline 2 & $\begin{array}{l}\text { Worst (extreme } \\
\text { pain/discomfort) }\end{array}$ & & 0.0885 & $7 \%$ & $\begin{array}{l}\text { Worst (extreme } \\
\text { pain/discomfort) }\end{array}$ & & -1.4975 & $3 \%$ \\
\hline Neither & & & & & $\begin{array}{l}\text { Extreme } \\
\text { pain/discomfort }\end{array}$ & $\begin{array}{l}\text { SUCCESS } 100 \% \text {, } \\
\text { SURVIVAL } 3 \mathrm{mth} \text {, } \\
\text { COST } \$ 0\end{array}$ & 0.812 & $34 \%$ \\
\hline \multicolumn{9}{|c|}{ Choice set two } \\
\hline 1 & $\begin{array}{l}\text { Best (no } \\
\text { pain/discomfort) }\end{array}$ & $\begin{array}{l}\text { Worst } \\
\text { (SUCCESS 60\% } \\
\text { SURVIVAL 3mth, } \\
\text { COST \$100,000) }\end{array}$ & 2.7106 & $75 \%$ & $\begin{array}{l}\text { Best (no } \\
\text { pain/discomfort) }\end{array}$ & $\begin{array}{l}\text { Worst } \\
\text { (SUCCESS 60\% } \\
\text { SURVIVAL 3mth, } \\
\text { COST \$100,000) }\end{array}$ & 1.4445 & $47 \%$ \\
\hline 2 & $\begin{array}{l}\text { Worst (extreme } \\
\text { pain/discomfort) }\end{array}$ & $\begin{array}{l}\text { Best } \\
\text { (SUCCESS 90\%, } \\
\text { SURVIVAL 10yr, } \\
\text { COST \$1,000) }\end{array}$ & 1.6171 & $25 \%$ & $\begin{array}{l}\text { Worst (extreme } \\
\text { pain/discomfort) }\end{array}$ & $\begin{array}{l}\text { Best } \\
\text { (SUCCESS 90\%, } \\
\text { SURVIVAL 10yr, } \\
\text { COST \$1,000) }\end{array}$ & 0.9496 & $28 \%$ \\
\hline Neither & & & & & $\begin{array}{l}\text { Extreme } \\
\text { pain/discomfort }\end{array}$ & $\begin{array}{l}\text { SUCCESS } 100 \% \text {, } \\
\text { SURVIVAL } 3 \mathrm{mth} \text {, } \\
\text { COST } \$ 0\end{array}$ & 0.812 & $25 \%$ \\
\hline
\end{tabular}




\section{References}

Alexander , K. and Hicks, N. (1998), "Sailing without radar: an excursion in resource allocation", Australian Health Review, Vol. 21 No. 2, pp. 76-99.

Anderson, C.J. (2003), "The psychology of doing nothing: forms of decision avoidance result from reason and emotion", Psychological Bulletin, Vol. 129 No. 1, pp. 139-67.

Arora, R. (2006), "Product positioning based on search, experience and credence attributes using conjoint analysis", Journal of Product and Brand Management, Vol. 15 No. 5, pp. 285-92.

Australian Bureau of Statistics (2003-04), Household Income and Income Distribution, Australia. Report No. 6523.0, Australian Bureau of Statistics, Canberra. $<$ www.abs.gov.au>

---- (2004-05), National Health Survey: Summary of Results. Report No. 4364.0, Australian Bureau of Statistics, Canberra. <www.abs.gov.au $>$

---- (2006a), Education and work: Australia. Report No. 6227.0, Australian Bureau of Statistics, Canberra. $<$ www.abs.gov.au $>$

---- (2006b), Population by Age and Sex, Australian States and Territories. Report No. 3201.0, Australian Bureau of Statistics, Canberra. <www.abs.gov.au $>$

Bennett, R. and Rundle-Thiele, S.R. (2004), "Customer satisfaction should not be the only goal", Journal of Services Marketing, Vol. 18 No. 7, pp. 514-23.

Bleichrodt, H., Doctor, J. and Stolk, E. (2005), "A nonparametric elicitation of the equityefficiency trade-off in cost-utility analysis", Journal of Health Economics, Vol. 24 No. 4, pp. 655-78.

Brau, R. and Bruni, M.L. (2008), "Eliciting the demand for long-term care coverage: a discrete choice modelling analysis", Health Economics, Vol. 17 No. 3, pp. 411-33. 
Browning, C.J. and Thomas, S.A. (2001), "Community values and preferences in transplantation organ allocation decisions", Social Science \& Medicine, Vol. 52 No. 6, pp. 853-61.

Bryan, S., Roberts, T., Heginbotham, C. and McCallum, A. (2002), "QALY-maximisation and public preferences: results from a general population survey", Health Economics, Vol. 11 No. 8, pp. 679-93.

Bunch, D.S., Louviere, J.J. and Anderson, D. (1996), A comparison of experimental design strategies for multinomial logit models: the case of generic attributes. Report No. UCD.GSM.WP\#11.96, Graduate School of Management, University of California, Davis, CA.

Daniels, N. and Sabin, J. (2002), Setting Limits Fairly: Can We Learn to Share Medical Resources?, Oxford University Press Inc, New York.

Dean, D.H. (2004), "Evaluating potential brand associations through conjoint analysis and market simulation", Journal of Product and Brand Management, Vol. 13 No. 7, pp. 506-13.

Department of Health and Aged Care (2001), Measuring Remoteness: Accessibility/remoteness Index of Australia (ARIA) (Revised ed.). Report No. 14, Commonwealth Department of Health and Aged Care, Canberra.

Dillman, D.A. (2000), Mail and Internet Surveys: the Tailored Design Method, 2nd edn, John Wiley \& Sons, Inc., New York.

Dolan, P., Shaw, R., Tsuchiya, A. and Williams, A. (2005), "QALY maximisation and people's preferences: a methodological review of the literature", Health Economics, Vol. 14 No. 2, pp. 197-208.

Dolan, P. and Tsuchiya, A. (2006), "The elicitation of distributional judgements in the context of economic evaluation", in Jones, A.M. (Ed.), The Elgar Companion to Health Economics, Edward Elgar Publishing Ltd, Cheltenham, pp. 382-91. 
Farrar, S., Ryan, M., Ross, D. and Ludbrook, A. (2000), "Using discrete choice modelling in priority-setting: an application to clinical service developments", Social Science and Medicine, Vol. 50 pp. 63-75.

Gallego, G., Taylor, S.J., McNeill, P. and Brien, J.E. (2007), "Public views on priority setting for high cost medications in public hospitals in Australia", Health Expectations, Vol. 10 No. 3, pp. 224-35.

Garber, A.M., Weinstein, M.C., Torrance, G.W. and Kamlet, M.S. (1996), "Theoretical foundations of cost-effectiveness analysis", in Gold, M.R., Siegel, J.E., Russell, L.B. and Weinstein, M.C. (Eds), Cost-effectiveness in Health and Medicine, Oxford University Press Inc., New York, pp. 25-53.

Gold, M.R., Franks, P., Siegelberg, T. and Sofaer, S. (2007), "Does providing costeffectiveness information change coverage priorities for citizens acting as social decision-makers?" Health Policy, Vol. 83 pp. 65-72.

Gold, M.R., Siegel, J.E., Russell, L.B. and Weinstein, M.C. (Eds) (1996), Cost-effectiveness in Health and Medicine, Oxford University Press Inc., New York.

Greene, W. (2007), Computer Program, NLOGIT, 4.0.1 edn, Econometric Software, Inc., Plainview, NY.

Gyrd-Hansen, P. (2004), "Investigating the social value of health changes", Journal of Health Economics, Vol. 23 No. 6, pp. 1101-16.

Haas, M. (2005), "The impact of non-health attributes of care on patients' choice of GP", Australian Journal of Primary Health, Vol. 11 No. 1, pp. 40-6.

Hadorn, D.C. (1991), "Setting health care priorities in Oregon. Cost-effectiveness meets the rule of rescue", Journal of the American Medical Association, Vol. 265 No. 17, pp. 2218-25.

Hair, J.F., Black, W.C., Babin, B.J., Anderson, R.E. and Tatham, R.L. (2006), Multivariate Data Analysis: International Edition, 6th edn, Pearson Prentice Hall, New Jersey. 
Hall, J., Fiebig, D.G., King, M.T., Hossain, I. and Louviere, J.J. (2006), "What influences participation in genetic carrier testing? Results from a discrete choice experiment", Journal of Health Economics, Vol. 25 No. 3, pp. 520-37.

Hanley, N., Mourato, S. and Wright, R. (2001), "Choice modelling approaches: a superior alternative for environmental valuation?" Journal of Economic Surveys, Vol. 15 No. 3, pp. 435-62.

Hensher, D.A., Rose, J.M. and Greene, W.H. (2005), Applied Choice Analysis: A Primer, Cambridge University Press, New York.

Johnson, F.R. and Backhouse, M. (2006), "Eliciting stated preferences for health-technology adoption criteria using paired comparisons and recommendation judgements", Value in Health, Vol. 9 No. 5, pp. 303-11.

Johri, M., Damschroder, L.J., Zikmund-Fisher, B.J. and Ubel, P.A. (2005), "The importance of age in allocating health care resources: does intervention-type matter?" Health Economics, Vol. 14 No. 7, pp. 669-78.

King, M.T., Hall, J., Lancsar, E., Fiebig, D., Hossain, I., Louviere, J., Reddel, H.K. and Jenkins, C.R. (2007), "Patient preferences for managing asthma: results from a discrete choice experiment", Health Economics, Vol. 16 No. 7, pp. 703-17.

Kjaer, T. (2005), A review of the discrete choice experiment - with emphasis on its application in health care, University of Southern Denmark. $<$ http://www.sam.sdu.dk/healtheco/publications/20051pdf.pdf $>$

Koo, L.C., Tao, F.K.C. and Yeung, J.H.C. (1999), "Preferential segmentation of restaurant attributes through conjoint analysis", International Journal of Contemporary Hospitality Management, Vol. 11 No. 5, pp. 242-50.

Lancsar, E.J., Hall, J.P., King, M., Kenny, P., Louviere, J.J., Fiebig, D.G., Hossain, I., Thien, F.C., Reddel, H.K. and Jenkins, C.R. (2007), "Using discrete choice experiments to investigate subject preferences for preventive asthma medication", Respirology, Vol. 12 No. 1, pp. 127-36. 
Mantovani, L.G., Monzini, M.S., Mannucci, P.M., Scalone, L., Villa, M. and Gringeri, A. (2005), "Differences between patients', physicians' and pharmacists' preferences for treatment products in haemophilia: a discrete choice experiment", Haemophilia, Vol. 11 No. 6, pp. 589-97.

Mitchell, A. (2002), "Antipodean assessment: activities, actions and achievements", International Journal of Technology Assessment in Health Care, Vol. 18 pp. 203-12.

Mooney, G.H. and Blackwell, S.H. (2004), "Whose health service is it anyway? Community values in healthcare", Medical Journal of Australia, Vol. 180 No. 2, pp. 76-8.

Mortimer, D. and Segal, L. (2008), "Is the value of a life of life-year saved context specific? Further evidence from a discrete choice experiment", Cost Effectiveness and Resource Allocation, In press.

National Institute for Health and Clinical Excellence (2004), Guide to the methods of technology appraisal, National Institute for Clinical Excellence, London. $<$ http://www.nice.org.uk/pdf/TAP_Methods.pdf $>$

---- (2005), Social value judgements: principles for the development of NICE guidance, National Institute for Health and Clinical Excellence, London. <www.nice.org.uk>

Nord, E. (1993), "The trade-off between severity of illness and treatment effect on cost-value analysis of health care", Health Policy, Vol. 24 pp. 227-38.

Nord, E., Richardson, J., Street, A., Kuhse, H. and Singer, P. (1995), "Who cares about cost? Does economic analysis impose or reflect social values?" Health Policy, Vol. 34 No. 2, pp. 79-94.

Nord, E., Street, A., Richardson, J., Kuhse, H. and Singer, P. (1996), "The significance of age and duration of effect in social evaluation of health care", Health Care Analysis, Vol. 4 No. 2, pp. 103-11.

Pharmaceutical Benefits Advisory Committee (2007), Guidelines for preparing submissions to the Pharmaceutical Benefits Advisory Committee (version 4.2), Australian Government Department of Health and Ageing, Canberra. 
$<$ http://www.aodgp.gov.au/internet/main/publishing.nsf/Content/pbacguidelinesindex $>$

Phillips, K.A., Maddala, T. and Johnson, F.R. (2002), "Measuring preferences for health care interventions using conjoint analysis: an application to HIV testing", Health Services Research, Vol. 37 No. 6, pp. 1681-705.

Rawlins, M.D. (2005), "Pharmacopolitics and deliberative democracy", Clinical Medicine, Vol. 5 No. 5, pp. 471-5.

Redelmeier, D.A. and Shafir, E. (1995), "Medical decision making in situations that offer multiple alternatives", Journal of the American Medical Association, Vol. 273 No. 4, pp. 302-5.

Robinson, A. and Parkin, D. (2002), "Recognising diversity in public preferences: the use of preference sub-groups in cost-effectiveness analysis. A response to Sculpher and Gafni", Health Economics, Vol. 11 No. 7, pp. 649-51.

Rodriguez-Miguez, E. and Pinto-Prades, J.L. (2002), "Measuring the social importance of concentration or dispersion of individual health benefits", Health Economics, Vol. 11 No. 1, pp. 43-53.

Rodriguez, E. and Pinto, J.L. (2000), "The social value of health programmes: is age a relevant factor?" Health Economics, Vol. 9 No. 7, pp. 611-21.

Rundle-Thiele, S.R. (2005), "Elaborating customer loyalty: Exploring loyalty to wine retailers", Journal of Retailing and Consumer Services, Vol. 12 No. 5, pp. 333-44.

Ryan, M. and Farrar, S. (2000), "Using conjoint analysis to elicit preferences for health care", British Medical Journal, Vol. 320 pp. 1530-3.

Ryan, M. and Gerard, K. (2003), "Using discrete choice experiments to value health care programmes: current practice and future research reflections", Applied Health Economics and Health Policy, Vol. 2 No. 1, pp. 55-64.

Ryan, M., Gerard, K. and Currie, G. (2006), "Using discrete choice experiments in health economics", in Jones, A.M. (Ed.), The Elgar Companion to Health Economics, Edward Elgar Publishing Ltd, Cheltenham, pp. 405-14. 
Ryan, M., Netten, A., Skåtun, D. and Smith, P. (2006), "Using discrete choice experiments to estimate a preference-based measure of outcome - an application to social care for older people", Journal of Health Economics, Vol. 25 pp. 927-44.

Ryan, M., Scott, D.A., Reeves, C., Bate, A., van Teijlingen, E.R., Russell, E.M., Napper, M. and Robb, C.M. (2001), "Eliciting public preferences for healthcare: a systematic review of techniques", Health Technology Assessment, Vol. 5 No. 5, pp. 1-186.

Ryan, M. and Skatun, D. (2004), "Modelling non-demanders in choice experiments", Health Economics, Vol. 13 No. 4, pp. 397-402.

Schwappach, D.L.B. (2002), "Resource allocation, social values and the QALY: a review of the debate and empirical evidence", Health Expectations, Vol. 5 No. 3, pp. 210-22.

---- (2003), "Does it matter who you are or what you gain? An experimental study of preferences for resource allocation", Health Economics, Vol. 12 No. 4, pp. 255-67.

Scuffham, P.A., Whitty, J.A., Mitchell, A. and Viney, R. (2008), "The use of QALY weights for QALY calculations: a review of industry submissions requesting listing on the Australian Pharmaceutical Benefits Scheme 2002 to 2004", Pharmacoeconomics, Vol. 26 No. 4, pp. 297-310.

SPSS (2005), Computer Program, SPSS for Windows, 14.0.0 edn, SPSS Inc., Chicago.

Tappenden, P., Brazier, J., Ratcliffe, J. and Chilcott, J. (2007), "A stated preference binary choice experiment to explore NICE decision making", Pharmacoeconomics, Vol. 25 No. 8, pp. 685-93.

Tsuchiya, A. (1999), "Age-related preferences and age weighting health benefits", Social Science and Medicine, Vol. 48 No. 2, pp. 267-76.

Ubel, P.A., Baron, J., Nash, B. and Asch, D.A. (2000), "Are preferences for equity over efficiency in health care allocation "all or nothing"?" Medical Care, Vol. 38 No. 4 , pp. 366-73.

Ubel, P.A., Loewenstein, G., Scanlon, D. and Kamlet, M. (1996), "Individual utilities are inconsistent with rationing choices: A partial explanation of why Oregon's costeffectiveness list failed", Medical Decision Making, Vol. 16 No. 2, pp. 108-16. 
WHO (2006), The World Health Report 2006: Working Together for Health, World Health

Organization, Geneva. <http://www.who.int/whr/2006/en/>

Williams, A. (1995), The measurement and valuation of health: a chronicle. Report No. 136, Centre for Health Economics, York. <http://www.york.ac.uk/inst/che/pdf/DP136.pdf>

Wiseman, V., Mooney, G., Berry, G. and Tang, K.C. (2003), "Involving the general public in priority setting: experiences from Australia", Social Science and Medicine, Vol. 56 No. 5, pp. 1001-12.

Wiseman, V. (2004), "Aggregating Public Preferences for Healthcare: Putting Theory into Practice", Applied Health Economics and Health Policy, Vol. 3 No. 3, pp. 171-79

\footnotetext{
${ }^{1}$ The preferred method of administration for this discrete choice experiment (for the pilot study) was through a personal interview. Personal administration enables understanding of the factors and the levels to be obtained (Hair et al., 2006).

${ }^{2}$ The nature of effects coding means we are unable to predict the sign for QoLE2, which may be greater or less than the normalised mean effect of zero; however, as QoLE1 is a more extreme level than QoLE2, it would be expected that the value of the coefficient for QoLE1 would be greater than that for QoLE2.

${ }^{3}$ In addition to the two respondents who did not respond to a total of 5 choice sets, a further two respondents expressed a wish to choose "neither" for some choice sets, but nevertheless responded to all sets. This led to a concern that not including an opt out option of "neither" in the choice sets might lead to non-response, and was the reason for including a "neither" option in the main study DCE design.

${ }^{4}$ The Quality-Adjusted Life Year (QALY) has gained popularity as the outcome measure of choice for economic evaluations of pharmaceuticals (Scuffham et al., 2008). Since April 2004, QALYs have been required by the National Institute for Health and Clinical Excellence in the United Kingdom in the economic evaluation of all healthcare interventions (including pharmaceuticals) being appraised (National Institute for Health and Clinical Excellence, 2004). In Australia, the PBAC encourage the use of the QALY as an outcome measure (although its use is not mandatory) (Pharmaceutical Benefits Advisory Committee, 2007).
} 